\title{
Histopathological Spectrum of Gall Bladder Lesions in A Tertiary Care Hospital in The Malwa Belt: A Hospital Based Study
}

\author{
ShaffyThukral ${ }^{1}$, Arnav Kr. Roychoudhury ${ }^{1 *}$, Nidhi Bansal ${ }^{2}$ and Ekta Rani ${ }^{1}$ \\ ${ }^{1}$ Dept. Of Pathology, Adesh Institute of Medical Sciences \& Research, Bathinda, India \\ ${ }^{2}$ Dept. Of Immunohematology \& Blood Transfusion, GGS Medical College \& Hospital, Faridkot. India
}

\section{ABSTRACT}

Introduction: Gallbladder stones are commonest disorder among gall bladder lesions and are usually asymptomatic. Its frequency in cholecystectomy specimens is not clear. The aim of this study was to report the morphological variants and frequency of different lesions in cholecystectomy specimens. Objective: To study the various histopathological spectrum of gall bladder lesions.

Materials and Methods: In present study we have studied total 141 cases of gall bladder lesion during the period of 6 months from April 2017 to October 2017 in the Dept. of Pathology at Adesh Institute of Medical Sciences and Research, Bathinda.

Results: Benign lesions of gall bladder outnumbered the malignant ones with non-neoplastic lesions accounting for $93.6 \%$ (132 cases) with chronic calculous cholecystitis contributing the majority of the non-neoplastic lesions (49.64\%) followed by cholesterolosis (22.69\%), acalculous cholecystitis (4.96\%), followed by gangrenous and xanthogranulomatous cholecystitis. Females were predominantly affected in the present study with total 107 cases out of 141 cases- $75.8 \%$ cases. Most of the non-neoplastic lesions of the gall bladder lesions are common in 3rd, 4th and 5th decades of life. Neoplastic lesions of the gall bladder were common in 5th, 6th and 7th decades of life. Out of 141 cases 5 cases are of adenocarcinoma of gall bladder-3.5\% of all cases. The mean age of patient with adenocarcinoma of gall bladder is 60.8 years.

Conclusion: Gall bladder lesions were common indication for surgical intervention and pathological evaluation. Most of them were inflammatory lesions with cholelithiasis, however thorough examination is important as these lesions may progress to fatal malignancies.

Keywords: Cholecystectomy, Cholecystitis, Adenocarcinoma

\section{Introduction}

The gall bladder is one of the most frequently resected organs in the gastrointestinal tract with a varied spectrum of diseases affecting it ranging from cholelithiasis, both inflammatory and non-inflammatory lesions to invasive as well as non-invasive neoplastic lesions. Cholelithiasis is one of the most common disorder affecting 10-20\% of adult populations in developed countries. ${ }^{[1]}$ In India cholelithiasis is more prevalent in north as compared to south affecting $10-20 \%$ of the population..$^{[1,2]}$ Non neoplastic lesions includes acute on chronic cholecystitis, chronic calculous cholecystitis, gangrenous cholecystitis, eosinophilic cholecystitis, xanthogranulomatous cholecystitis, cholesterol polyp, cholesterolosis, empyema, choledochal cyst, metaplasia and focal mucosal hyperplasia. Neoplastic conditions includes inflammatory pseudotumor, adenocarcinoma and neuroendocrine carcinoma.

Cholecystitis associated with cholelithiasis is a common disease particularly found in fertile and fatty females in their forties, however it can also affect males and children. This condition has increased in the past two decades due to increase intake of unhealthy fat rich food, lack of exercise, obesity and sedentary lifestyle. ${ }^{[3]}$

\section{Materials \& Methods}

The study was conducted at Department of Pathology at Adesh Institute of Medical Sciences, Bathinda for a period of 6 months from April 2017 to October 2017. Laparoscopic and open resection specimens of Gall bladder were received in $10 \%$ formalin in the Dept. of Histopathology. After routine tissue processing and staining with Haematoxylin and Eosin, histopathology reports were analyzed for different histopathological lesions by two eminent pathologists. Special stains were done when ever required for confirmation. Data regarding age, gender, pre-cholecystectomy ultrasound or CT findings for any suspicion of carcinoma or mass gall bladder was obtained from the request forms of the patients while subsequent histopathology results of the gall bladder specimens were retrieved from computer of the concerned histopathology section. The data was entered into and analyzed by Microsoft Excel software.

\section{Results}

A total of 141 patients who had undergone cholecystectomy during the above mentioned six months were included. Among these patients, majority (75.8\%) were female and only $24.1 \%$ were male. The age of the patients ranged from 20 to 85 years. 
Non-neoplastic lesions (93.6\%) constitute the majority of the cholecystectomy specimens followed by few cases of neoplastic lesions $(6.38 \%)$. Benign tumors contributed $22.2 \%$, whereas Malignant tumors comprised of $77.7 \%$ of all the neoplastic lesions. Among all the cholecystectomy specimens the carcinoma gall bladder contributed 4.96\% of all cases. Details of the histopathological findings with number of cases are shown in Table 1.

Histopathological observations from all the submitted cholecystectomy specimens showed Cholecystitis as the most common benign non-neoplastic lesion comprising of 83 cases (58.8\%) of all the cholecystectomy specimens with Chronic Calculous Cholecystitis being the major contributor, 70 cases ( 49.64\%) followed by 7 cases $(4.96 \%)$ of acalculous cholecystitis, 3 cases $(2.12 \%)$ of granulomatous cholecystitis and 1 case $(0.71 \%)$ each of acute-on-chronic cholecystitis, eosinophilic cholecystitis and xanthogranulomatous cholecystitis.

Among the 70 cases of Chronic Calculous Cholecystitis 53 cases showed pigmented stones, 10 were cholesterol and remaining 7 cases were of mixed variety.
Cholesterolosis presented as the 2nd most common benign lesion comprising of 32 cases $(22.69 \%)$ of all cholecystectomy specimens. Hyperplasia constituted 6 cases $(4.25 \%)$ followed by 5 cases $(3.54 \%)$ of metaplasia.

Among the pre-malignant lesions of the Gallbladder, hyperplasia was the most common followed closely by metaplasia contributing to 11 cases of non-neoplastic category. Two cases of inflammatory pseudo-tumor were also seen in our study. Adenocarcinoma (3.54\%) was the most common malignant lesion followed by two cases of neuroendocrine carcinoma of Gallbladder (1.41\%).

Age wise distribution of gall bladder histopathological lesions with special reference to pre-malignant (hyperplasia, metaplasia) and malignant lesions are being shown in table 2.

Incidence of Gall bladder pre-malignant and malignant lesions have been shown in table 3 .

\section{Discussion}

Gallbladder disease is the most common surgical disorder that requires elective surgery, either open or laparoscopic

Table 1: Details of the histopathological findings with number of cases.

\begin{tabular}{|l|c|c|}
\hline LESION & NO. OF CASES & PERCENTAGES \\
\hline Acute on chronic cholecystitis & 1 & $0.71 \%$ \\
\hline Chronic calculous cholecystitis & 70 & $49.64 \%$ \\
\hline Chronic acalculous cholecystitis & 7 & $4.96 \%$ \\
\hline Gangrenous cholecystitis & 3 & $2.12 \%$ \\
\hline Eosinophilic cholecystitis & 1 & $0.71 \%$ \\
\hline Xanthogranulomatous cholecystitis & 1 & $0.71 \%$ \\
\hline Cholesterolosis & 32 & $22.69 \%$ \\
\hline Empyema & 1 & $0.71 \%$ \\
\hline Cholesterol polyps & 3 & $2.12 \%$ \\
\hline Choledochal cyst & 1 & $0.71 \%$ \\
\hline Mucosal hyperplasia & 6 & $4.25 \%$ \\
\hline Metaplasia & 5 & $3.54 \%$ \\
\hline Inflammatory pseudotumor & 2 & $1.41 \%$ \\
\hline Adenocarcinoma gall bladder & 5 & $3.54 \%$ \\
\hline Neuroendocrine carcinoma & 2 & $1.41 \%$ \\
\hline TOTAL & 141 & $\mathbf{1 0 0} \%$ \\
\hline
\end{tabular}

TABLE 2: Incidence of gall bladder premalignant and malignant lesions

\begin{tabular}{|l|c|c|}
\hline LESION & MALE & FEMALE \\
\hline BENIGN TUMOR & $2(40 \%)$ & $3(60 \%)$ \\
\hline PREMALIGNANT & $6(54.54 \%)$ & $5(45.45 \%)$ \\
\hline MALIGNANT & $3(42.85 \%)$ & $4(57.1 \%)$ \\
\hline
\end{tabular}


Table 3: Age wise distribution of gall bladder histopathological lesions with special reference to pre-malignant (hyperplasia, metaplasia) and malignant lesions

\begin{tabular}{|c|c|c|c|c|c|c|}
\hline $\begin{array}{l}\text { AGE } \\
\text { GROUPS } \\
\text { (YEARS) }\end{array}$ & HYPERPLASIA & METAPLASIA & $\begin{array}{l}\text { INFLAMMATORY } \\
\text { PSEUDOTUMOR }\end{array}$ & ADENOCARCINOMA & $\begin{array}{l}\text { NEUROENDOCRINE } \\
\text { CARCINOMA }\end{array}$ & OVERALL \\
\hline $20-29$ & $1(16.7 \%)$ & - & - & $1(20 \%)$ & - & $2(10 \%)$ \\
\hline $30-39$ & $3(50 \%)$ & - & - & $1(20 \%)$ & - & $4(20 \%)$ \\
\hline $40-49$ & - & $3(60 \%)$ & - & - & - & $3(15 \%)$ \\
\hline $50-59$ & - & $2(40 \%)$ & $1(50 \%)$ & - & $1(50 \%)$ & $4(20 \%)$ \\
\hline $60-69$ & $2(33.3 \%)$ & - & $1(50 \%)$ & $2(40 \%)$ & $1(50 \%)$ & $6(30 \%)$ \\
\hline $70-79$ & - & - & - & $1(20 \%)$ & - & $1(5 \%)$ \\
\hline $80-89$ & - & - & - & - & - & $0(0 \%)$ \\
\hline TOTAL & $6(100 \%)$ & $5(100 \%)$ & $2(100 \%)$ & $5(100 \%)$ & $2(100 \%)$ & $20(100 \%)$ \\
\hline
\end{tabular}

cholecystectomy. The specimens are received in each histopathology laboratory, where they are evaluated for various pathological lesions. The estimated prevalence of the disease in India is reported to be between $2 \%$ and $29 \%{ }^{[4]}$ The present study was conducted on 141 cholecystectomy specimens to determine the histopathological spectrum of gallbladder disease. Histopathology is the gold standard for diagnosis and planning of future treatment modality. In our present study, the age of the patients ranged from 20 to 85 years. Maximum number of patients was in the fourth decade of their life. Male to female ratio was 1:3.1 in the present study which was in concordance with the studies conducted by Mohan et al and Siddique et al. ${ }^{[4,5]}$

The high incidence of gallbladder disease in females are because of the sedentary life styles and female sex hormones which expose the females to the formation of gallstones. ${ }^{[4]}$ Chronic cholecystitis was the most common diagnostic entity comprising of $115(81.5 \%)$ cases which included various histopathological spectrum like Chronic calculous cholecystitis, chronic acalculous cholecystitis, cholesterolosis, gangrenous cholecystitis, eosinophilic cholecystitisand xanthogranulomatous cholecystitis. The findings of our study was in concordance to the studies conducted by Siddiqui et $\mathrm{al}^{[5]}$ and ThamilSelvi et $\mathrm{al}^{\left[{ }^{[6]}\right.}$ and who also reported chronic cholecystitis as the most common histopathological finding in their study as well.

Xanthogranulomatous cholecystitis is a rare form of chronic cholecystitis which mimics gallbladder cancer although it is not cancerous. It was first discovered and reported in the medical literature in 1976 by J.J. McCoy, Jr., and colleagues. ${ }^{[7]}$
Our study showed gangrenous cholecystitis in $3(2.12 \%)$ cases which was similar to the findings of the study conducted by Nidimusili et al and Kayyali et al. ${ }^{[8,9]}$ Gangrenous cholecystitis is the end result of gall bladder inflammation that starts from vascular compromise and progresses to ischemia, necrosis and ultimately perforation of the gall bladder wall. Diabetes mellitus, associated cardiovascular diseases, and advanced age are some of the key factors that causes increase in the probability of gangrenous cholecystitis. ${ }^{[10]}$

\section{Conclusion}

Gall bladder lesions were common indication for surgical intervention and pathological evaluation. Most of them were inflammatory lesions with cholelithiasis, however thorough examination is important as these lesions may progress to fatal malignancies.

\section{References}

1. Bladder G. Extrahepatic biliary tree and ampulla. In: Mills SE, editor. Sternberg's Diagnostic Surgical Pathology. 5th ed., Vol. II. Wolters Kluwer, 2010. p. 1600-51.

2. Epidemiological Study of Cholelithiasis: Indian context By Dr S.R. Mhamunkar, Dr.R.D. Bapat, Ms. S.P. Mahadik, Dr. B.A. Abhyankar

3. Rosai and Ackerman's Surgical Pathology,9th Ed. Vol I:1041.

4. Mohan H, Punia RP, Dhawan SB, Ahal S, Sekhon MS. Morphological spectrum of gallstone disease in 1100 cholecystectomies in North India. Indian J Surg 2005;67:140-2.

5. Siddiqui FG, Memon AA, Abro AH, Sasoli NA, Ahmed L. Routine histopathology of gallbladder after elective cholecystectomy of gallstones; waste of resources or justified act? BMC Surgery 2013;13(26):1-7. 
6. Thamil Selvi et al. A clinicopathological study of cholecystitis with special reference to analysis of cholelithiasis. International Journal of Basic Medical Science 2011:2,68-72.

7. McCoy JJ, Vila R, Petrossian G, McCall RA, Reddy KS; Vila, et al. Xanthogranulomatous cholecystitis. Report of two cases. J S C Med Assoc. 1976;72(3):78-9.

8. Nidimusili AJ, Alraies MC, Eisa N, Alraiyes AH, Shaheen K.
Leukocytosis of unknown origin: Gangrenous cholecystitis. Case Rep Med 2013; 1:1-4.

9. Kayyali A, Toumeh A, Jiang Y, Yousef W. Gangrenous cholecystitis: a case report. TranslGastrointest Cancer 2013; 2:167-9.

10. Narang A, Garg P, Bhoriwal S, Rathi V, Aggarwal S, MittalS et al. Various presentations of gangrenous cholecystitis and review of literature. Int J Surgery 2012; 28: 1-4

*Corresponding author:

Arnav Kr. Roychoudhury, Dept. Of Pathology, Assistant Professor, Adesh Institute of Medical Sciences \& Research, NH-7, Barnala Road, Bathinda 151101 INDIA

Phone: +918054387212

Email: drarnav2007@gmail.com

Financial or other Competing Interests: None. 